\title{
Corneal Infections-Challenges in Diagnosis and Update on Management
}

\author{
An Expert Interview with Bennie $\mathrm{H}$ Jeng \\ Department of Ophthalmology and Visual Sciences, University of Maryland School of Medicine, Baltimore, Maryland, us
}

DOl: https://doi.org/10.17925/USOR.2017.10.01.15

\begin{abstract}
Bennie H Jeng
Bennie H Jeng is Professor and Chair of the Department of Ophthalmology and Visual Sciences at the University of Maryland School of Medicine. He earned his bachelor's degree summa cum laude from Washington University and his MD from the University of Pennsylvania School of Medicine. He then completed his ophthalmology residency and chief residency at the Cole Eye Institute of the Cleveland Clinic, which was followed by a fellowship in cornea and external diseases at the Francis I. Proctor Foundation/University of California San Francisco (UCSF) in 2003. He then returned back to the Cole Eye Institute to serve on faculty, during which time he was the recipient of a K-grant from the NIH and also earned his Master degree in Clinical Investigation. He subsequently returned to Proctor/UCSF as an Associate Professor and then Full Professor, where he served as co-director of the UCSF cornea service, Director of the Proctor/UCSF Cornea Fellowship program, and as Chief of Ophthalmology at the San Francisco General Hospital. He was an R01-funded researcher at UCSF, and he assumed his current position at the University of Maryland in August, 2013.
\end{abstract}

Dr Jeng is actively involved in the leadership of many of our ophthalmologic societies, including as a member of the Board of Directors of the Cornea Society, the Eye Bank Association of America, and the Contact Lens Association of Ophthalmologists. He also serves on several committees of the American Academy of Ophthalmology, including the Annual Meeting Program Committee, as well as The Council. He is also actively involved with the American Board of Ophthalmology. Dr Jeng is a past member of the editorial board of JAMA Ophthalmology, and he currently serves on the editorial boards of Ophthalmology, Eye, Cornea, Eye and Contact Lens (as an Associate Editor), and International Journal of Eye Banking.

\section{Keywords}

Corneal infections, keratitis, management, diagnosis, Descemet stripping endothelial keratoplasty

Disclosure: Bennie H Jeng has nothing to disclose in relation to this article. No funding was received in the publication of this article. This is an expert interview and as such has not undergone the journal's standard peer review process.

Acknowledgments: Medical writing assistance was provided by Katrina Mountfort, Freelance Medical Writer, supported by Touch Medical Media.

Authorship: All named authors meet the International Committee of Medical Journal Editors (ICMJE) criteria for authorship of this manuscript, take responsibility for the integrity of the work as a whole, and have given final approval to the version to be published. open Access: This article is published under the Creative Commons Attribution Noncommercial License, which permits any noncommercial use, distribution, adaptation, and reproduction provided the original author(s) and source are given appropriate credit.

Received: February 17, 2017

Published Online: March 27, 2017

Citation: US Ophthalmic Review, 2017;10(1):15-6

Corresponding Author: Bennie H Jeng, Department of Ophthalmology and Visual Sciences, 419 West Redwood St, Suite 470, Baltimore, Maryland 21201, US. E: bjeng@som.umaryland.edu
$\mathrm{K}$ eratitis can be the result of bacterial, fungal, viral or even amoebic infection of the cornea. Infectious keratitis requires urgent medical attention to prevent vision loss. Advances in diagnosis and treatment have improved outcomes but antibiotic resistance, as well as fungal, acanthamoebal, and viral keratitis remain problematic. In an expert interview, Dr Bennie $\mathrm{H}$ Jeng of the University of Maryland School of Medicine discusses the latest developments in the diagnosis and treatment of these challenging conditions.

\section{Q: What is the best approach for the management of antibiotic resistance in bacterial keratitis?}

Antibiotic resistance is increasing globally, but to a much lesser extent for ophthalmology. However, there are an increasing number of reports of bacterial infections of the cornea that have demonstrated resistance to various available antibiotics. ${ }^{1}$ In particular, Methicillin-resistant Staphylococcus aureus (MRSA) has been found to be widely resistant to the topical fluoroquinolones (FQ's), especially to the earlier generation FQ's such as ciprofloxacin or ofloxacin, but even to the newer generation moxifloxacin and gatifloxacin., ${ }^{2,3}$ While MRSA is generally sensitive to polymixin-trimethoprim $B,{ }^{2}$ the penetration of this antibiotic into the cornea is inferior to that of FQ's. For cases of bacterial keratitis caused by MRSA, extemporaneously compounded vancomycin is a good choice.

When confronted by a case of bacterial keratitis, management depends on the particular scenario. Small peripheral cases can be treated with a 4 th generation FQ. Larger peripheral $(>3 \mathrm{~mm})$ or central bacterial ulcers, or those anywhere in the setting of a corneal graft, should be cultured and then treated aggressively with extemporaneously compounded fortified antibiotic combinations such as vancomycin (due to the high rate of MRSA nowadays, cefazolin is being used less frequently), along with tobramycin or ceftazidime. If culture results demonstrate bacteria resistant to the therapy being used and the clinical situation is worsening, a change in therapy is warranted.

\section{Q: Can you tell us a little about fungal keratitis and the latest developments in its diagnosis and management?}

Fungal keratitis is a challenging condition, and a high suspicion for the condition, as well as aggressive treatment are necessary to ensure positive outcomes. Adding to the challenge 
is the fact that in the US, only natamycin is commercially available as a topical ophthalmic antifungal medication. Other antifungals such as voriconazole or amphotericin B need to be compounded extemporaneously. In addition, amphotericin B can be very toxic. Diagnosis can be challenging because cultures can be unrewarding. Newer technology such as confocal imaging may be a viable adjunct for the diagnosis of fungal keratitis.

In the hotter and more humid areas of the world, filamentous fungal species such as fusarium and aspergillus are more commonly seen. In contrast, in temperate areas, and in immunocompromised individuals, yeast such as candida species is more common. As such, treatment regimen may vary depending on the location and species involved.

The recent Mycotic Ulcer Treatment Trial (MUTT) demonstrated that visual acuity outcomes and adverse events were more favorable in eyes treated with topical natamycin compared to topical voriconazole, but this was in a group of eyes with predominantly filamentous fungal infections. ${ }^{4}$ As such, more studies are needed to evaluate outcomes of various antifungals with fungal keratitis caused by yeast, where many practitioners at this point will consider amphotericin B as a first line therapy. ${ }^{5}$

\section{Q: The incidence of fungal keratitis after Descemet stripping endothelial keratoplasty is increasing. How is this challenge being addressed?}

The increased incidence of fungal keratitis after Descemet stripping endothelial keratoplasty (DSEK) is multifactorial. The interface between the graft and the host stroma can serve as a protected environment where fungi can become trapped and proliferate. In addition, there is not an antifungal additive in currently commercially available hypothermic corneal storage media. ${ }^{6}$ Finally, the process of re-warming the corneal tissue for pre-cutting in the eye bank may allow for any fungi on the tissue to proliferate (in the storage media without antifungal additives).

There has been increasing interest in addressing this situation with studies on adding amphotericin B or another antifungal agents into the currently available hypothermic storage media.7.8 In the meantime, a heightened awareness of this condition, along with aggressive treatment upon identification of fungal keratitis is needed. Donor rim cultures only yield positive fungal cultures in $0.07 \%$ of cases, but cultures of donor rims should still be considered to check for fungal contamination as a positive donor rim may be associated with a resultant infection in approximately $17 \%$ of cases [unpublished data, Anthony J Aldave and The Eye Bank Association of America].

\section{Q: Acanthamoeba keratitis is often misdiagnosed. How can the diagnostic procedure be improved?}

Acanthamoeba keratitis (AK) is frequently misdiagnosed in the early stages of infection because the clinical appearance can either be non-descript, or it can mimic herpetic keratitis. A heightened awareness to consider this condition can lead to earlier diagnosis and better outcomes. As such, risk factors for the development of AK such as contact lens wear (especially soft contact lens wear), as well as exposure to bodies of fresh water, should be elicited from the patient. In addition, an understanding of the early appearance of $A K$ is essential: frequently, AK is only considered when a stromal ring infiltrate is seen on examination, but by this point, the infection is already in the later stages. A non-specific keratitis,along with pain (many times out of proportion to clinical findings), and a history with risk factors should point the practitioner to consider the diagnosis of AK. 9,10

Even when the suspicion is high, confirmation can be difficult as cultures are sometimes unrewarding in terms of a high false negative rate. Confocal imaging has been found to be a good adjunctive diagnostic tool, but it is not readily available to everyone, and it requires a skilled interpreter for the images.11 Polymerase chain reaction technology is also available experimentally in some areas. When necessary, corneal biopsy with histopathologic evaluation is warranted to help confirm the diagnosis of AK.

\section{Q: The differential diagnosis of VZV or HSV keratitis is also challenging. How can these be distinguished?}

Differentiating between varicella zoster virus (VZV) keratitis and herpes simplex virus (HSV) keratitis can be challenging. Although the clinical appearance of the viral infections in epithelial disease are generally more easily distinguished (the classic dendrite in HSV keratitis compared to the pseudodendrite in VZV keratitis), stromal involvement can appear similar in both scenarios. ${ }^{12-15}$

In instances where the clinical appearance is similar, patient history can be very helpful, as a patient with a confirmed prior history of HSV eye infection will likely (but not always) have HSV keratitis. Similarly, in a patient with a history of a skin rash affecting the first division of the fifth cranial nerve, VZV keratitis is more likely. However, it must be remembered that VZV keratitis can occur in a setting without a history of a zoster skin rash (zoster sine herpete).

While the treatment of VZV keratitis requires higher antiviral dosing than for HSV keratitis, when in doubt, treatment with the higher dose is warrented, and it is generally safe. Inflammation resulting from either viral infection is treated similarly with topical corticosteroid drops.
1. Miller D, Chang JS, Flynn HW, Alfonso EC, Comparative In Vitro Susceptibility of Besifloxacin and Seven comparators Against Ciprofloxacin- and Methicillin-Susceptible/ Nonsusceptible Staphylococci, J Ocul Pharmacol Ther 2013;29:339-44.

2. Asbel PA, Colby KA, Deng S, et al., Ocular TRUST: Nationwide Antimicrobial Susceptibility Patterns in Ocular Isolates, Am J Ophthalmol, 2008;145:951-8.

3. Elsahn AF, Yildiz, EH, Jungkind DL, et al., In Vitro Susceptibility Patterns of Methicillin-Resistant Staphylococcus aureus and Coagulase-Negative Staphylococcus Corneal Isolates to Coagulase-Negative Staphylococcus

4. Prajna, NV, Krishnan T, Mascarenhas J, et al., The Mycotic Ulcer Treatment TrialA Randomized Trial Comparing Natamycin vs Voriconazole, JAMA Ophthalmol, 2013:131:422-9.

5. Sharma S, Das S, Virdi A, et al., Re-appraisal of topical $1 \%$ voriconazole and $5 \%$ natamycin in the treatment of fungal keratitis in a randomised trial, $\mathrm{Br}$ I Ophthalmol, 2015;99:1190-5.

6. Aldave AJ, DeMatteo J, Glasser DB, et al., Report of the Eye Bank Association of America Medical Advisory Board Subcommittee on Fungal Infection After Corneal Transplantation, Cornea, 2013;32:149-54.

7. Layer N, Cevallos V, Maxwell AJ, et al., Efficacy and Safety of Antifungal Additives in Optisol-GS Corneal Storage Medium, JAMA Ophthalmol, 2014;132:832-7.

8. Duncan KE, Parker J, Hoover C, et al., The Effect of Light Exposure on the Efficacy and Safety of Amphotericin B in Corneal Storage on the Efficacy and Safety of Amphotericin

9. Yoder JS, Verani J, Heidman N et al., Acanthamoeba keratitis: Yoder JS, Verani J, Heidman N, et al., Acanthamoeba keratitis: Ophthalmic Epidemiol, 2012;19:221-5.

10. Dart JK, Saw VPJ, Kilvington S, Acanthamoeba Keratitis: Diagnosis and Treatment Update 2009, Am J Ophthalmol, 2009;148:487-99.

1. Nieder RL, McGhee CNJ, Clinical in vivo confocal microscopy of the human cornea in health and disease, Prog Retin Eye Res, 2010;29:30-58.

12. Miserocchi E, Fogliato G, Bianchi I, et al., Clinical Features of Ocular Herpetic Infection in an Italian Referral Center, Cornea, 2014;33:565-70

13. Baratz $\mathrm{KH}$, The Role of Antiviral Therapy After the Resolution of Acute Herpes Simplex Keratitis or Acute Herpes Zoster Ophthalmicus, Arch Ophthalmol, 2012:130:108-10

14. Liesegang TJ, Herpes zoster virus infection, Curr Opin Ophthalmol, 2004;15:531-6.

15. Edell AR, Cohen EJ et al., Herpes Simplex and Herpes Zoster Eye Disease: Presentation and Management at a City Hospital for the Underserved in the United States, Eye Contact Lens, 2013;39:311-4. 